\title{
Community Schools: New Perspectives on the Wraparound Approach
}

\author{
Nadine A. Bartlett and Trevi B. Freeze \\ University of Manitoba
}

\begin{abstract}
An increasing number of children and youth have mental health disorders. To address this issue, federal and provincial mental health policymakers in Canada have recommended: (a) improving the coordination of services, and (b) increasing the role that schools play in providing supports. One way to operationalize these recommendations is to implement the wraparound approach in the context of a full-service community school. This qualitative, multiple-case study of three community schools in Manitoba, Canada, explores the experiences of stakeholders in community schools as they relate to support for children and youth with mental health disorders and their families. The findings indicate that community schools engage in practices that align with the 10 guiding principles of wraparound. Given the broad-based partnerships in community schools and their focus on collaborative action, they hold promise as sites with the potential to lead the implementation of the wraparound approach.
\end{abstract}

An increasing number of children and youth are experiencing mental health disorders (Chartier et al., 2016; Waddell, Shepherd, Schwartz, \& Barican, 2014). It is estimated that as many as $20 \%$ of children and youth will experience a mental health disorder, and of those, only one in five will receive the support that they require (Mental Health Commission of Canada, 2013). Mental health disorders among children and youth contribute to many negative life outcomes that often persist into adulthood with significant social and economic costs (Waddell, McEwan, Shepherd, Offord, \& Hua, 2005). These findings have led to a sense of urgency in addressing the mental health needs of children and youth by governments in Canada. Provincial and federal mental health strategies in Canada, including Rising to the Challenge: A Strategic Plan for the 
Mental Health and Well-Being of Manitobans (Manitoba Health, 2011); Open Minds, Healthy Minds: Ontario's Comprehensive Mental Health and Addictions Strategy (Government of Ontario, 2011); and The Mental Health Strategy for Canada (MHSC; Mental Health Commission of Canada, 2012), have been developed in an effort to guide the provision of support for this population.

While these mental health strategies are multi-faceted, two common themes emerge in these documents: (a) the need for greater coordination of mental health services for children and youth, and (b) the need to enhance the role that schools play in the provision of these much-needed supports. These strategic directions in Canada align with the priorities and practices of other countries such as Australia, United Kingdom, Italy, New Zealand, and the United States. In these countries, multi-year mental health strategies have been developed to address this burgeoning issue (Adams, Daniels, \& Compagni, 2009). In a nutshell, there appears to be consensus that supporting children and youth with mental health disorders requires the coordinated and co-operative efforts of various individuals, social groups, and support services within the context of a school. In addition, frameworks for policy and funding initiated by the provincial and federal government also are required.

\section{Principles of the Wraparound Approach}

One way to operationalize the provision of integrated support for individual children and youth with mental health disorders is through the implementation of the wraparound approach. The wraparound approach is defined as

a philosophy of care that includes a definable planning process involving the child and family that results in a unique set of community services and natural supports individualized for that child and family to achieve a positive set of outcomes. (Burns \& Goldman, 1999, p. 27)

There are 10 guiding principles that provide the philosophical base of the wraparound approach. Each of the 10 guiding principles of the wraparound approach are listed and defined in Table 1. These principles have been accepted by human services and caregivers and have been endorsed by the National Wraparound Initiative (NWI). The NWI is an organization that promotes "understanding about the components and benefits of care coordination using the wraparound practice model and ... provide[s] the field with resources and guidance that facilitate high quality and consistent wraparound implementation" (National Wraparound Initiative, n.d., Mission, para 2).

\section{Wraparound Implementation}

The wraparound approach is implemented in nearly $90 \%$ of the states in the United States (Bruns, Sather, Pullmann, \& Stambaugh, 2011), and to a lesser degree, in other countries including Canada, Norway, Australia, New Zealand, and the United Kingdom. The widespread adoption of the wraparound approach in the United States can be attributed in large part to the recognition by the federal government that care coordination using wraparound is a promising approach that may lead to improvements in mental health outcomes and to reduced costs (Simons, Pires, Hendricks, \& Lipper, 2014). 
Table 1

Guiding Principles of Wraparound

Wraparound Principle
1. Voice and choice

Definition

1. Voice and choice

The child/youth and his or her family are central to the wraparound process. Team members work to set goals and develop support plans that are reflective of the family's perspectives, values, and preferences.

2. Team based

The wraparound team consists of individuals selected by the family. Teams often consist of informal members (e.g., extended family and friends), formal members (e.g., school-based professionals), and community supporters (e.g., community based professionals, elders).

3. Natural supports

Participation from the family's informal, formal, and community supports is encouraged. These natural supports are engaged and directly related to the planning of activities and interventions.

4. Collaboration

Team members work together to develop, implement, monitor, and evaluate the youth's wraparound plan.

5. Community based Plans are designed to be inclusive, responsive, accessible, and safe. Supporting the child/youth, his or her family, and his or her community involvement is an important component of the wraparound plan.

6. Culturally competent

7. Individualized

8. Strength based

9. Unconditional

10. Outcome based
The wraparound team demonstrates respect for and builds on the values, preferences, beliefs, culture, and identity of the child/youth and family and of their community.

Interventions, activities, strategies, supports, and services are selected purposefully to meet the needs and preferences of the child/youth and family.

Team members identify and employ the strengths of the child/youth, his or her family, and their community when developing the wraparound plan. The strengths and assets of individual team members are also considered.

The wraparound team supports the child/youth and his or her family through challenges and setbacks. Rejection and blame do not occur during the wraparound process and failure is not used to abandon the wraparound process. The team continues to work toward their goals until all members agree that formal wraparound is no longer required.

The team ensures that goals are connected to observable and measurable indicators of success. This data is used to monitor child/youth progress and make changes to the plan.

Adapted from Bruns et al. (2008)

Initiatives in the United States, which support the provision of school-wide and districtwide programming, also align with the philosophy and practice model of wraparound and have contributed to its implementation. For example, wraparound has been integrated into the indicated or intensive level of support outlined the Positive Behaviour Interventions and Supports (PBIS) implementation framework to support students with complex emotional and behavioural needs and their families (Eber, Hyde, \& Suter, 2011; Eber, Sugai, Smith, \& Scott, 2002;). Moreover, several funding sources in the United States support the implementation of wraparound including Medicare, Medicaid, and some private health insurance plans. The 21 st Century Community Learning Centers 
program, and the Elementary and Secondary Education Act are additional sources of federal funding in the United States that support the development of innovative wraparound services. Legislation including the Every Student Succeeds Act of 2015, which replaced the No Child Left Behind Act, emphasizes a whole-child approach to education, and among its provisions, provides opportunities to braid funds for implementation of holistic support like wraparound through Titles I and IV grants (Federation for Community Schools at Children's Home and Aid, 2017). In addition to federal funding, state and local level resources are available to support wraparound, particularly when alternatives to out-of-home care for individuals with mental health needs are identified (Conklin, 2008). It is evident that the variability in service delivery and funding mechanisms across jurisdictions affects the degree to which wraparound has been implemented.

\section{Research Evidence Supporting the Wraparound Approach}

According to Bruns and Suter (2010), prior to 2010 there had been nine controlled experimental and quasi-experimental studies on the wraparound approach, most of which examined the impact of the wraparound approach on children and youth with mental health disorders (Bruns, Rast, Peterson, Walker, \& Bosworth, (2006); Carney \& Buttell, 2003; Clark, Lee, Prange, \& McDonald, 1996; Clark et al., 1998; Evans, Armstrong, Kuppinger, Huz, \& McNulty, 1998; Hyde, Burchard, \& Woodworth, 1996; Mears, Yaffe, \& Harris, 2009; Myaard, Crawford, Jackson, \& Alesi, 2000; Pullman et al., 2006). Based on these studies, available evidence favours the wraparound approach (i.e., reduction in problematic behaviours, improvements in school performance and improvements in family functioning) over other interventions. There also is evidence that adherence to the 10 guiding principles of wraparound and to the practice model as measured through the Wraparound Fidelity Index may lead to more favourable outcomes for children, youth, and families (Bruns, Suter, Force, \& Burchard, 2005; Pagkos, 2011). Given that model adherence may lead to improvements in outcomes for children, youth, and families; further research is required to understand the conditions that may enable the implementation of high-fidelity wraparound.

While the research on the wraparound approach as a whole is quite extensive (Walker, Bruns, \& Penn, 2008) and includes studies involving child welfare, youth justice, primary care, and school settings, most of the research examines the implementation of the wraparound approach in mental health settings (Schurer Coldiron, Bruns, \& Quick, 2017). This is largely due to the fact that the population served by these providers includes children and youth with mental health disorders. However, there are many barriers to the receipt of mental health support in mental health settings. For example, the stigma associated with the receipt of support may act as a barrier for some (Schachter et al., 2008). For others, access may be hindered by multiple entry points and service fragmentation (Chartier et al., 2016) or by challenges related access and accessibility (Kirby \& Keon, 2006). Given these obstacles, it is necessary to explore alternative, inclusive settings, such as inclusive schools, which may be more conducive to the provision of highly integrated support. The following section presents schools as a viable location for the provision of the wraparound approach. 


\section{Schools as Host Environments for Wraparound}

Schools have been identified as holding much promise in the provision of mental health support (Mental Health Commission of Canada, 2012; National Research Council and Institute of Medicine, 2009; World Health Organization, 2013), and also have been found to have potential to lead the implementation of the wraparound approach (Eber et al., 2011; Eber et al., 2002; Scott \& Eber, 2003). There are several reasons why schools may be ideal host environments for the coordination and provision of these services. For one, there may be fewer stigmas around school support services (Harbin, McWilliam, \& Gallagher, 2000). Given schools' daily contact with children and youth, Whitley \& Gooderham (2016) emphasized the important role that teachers may play in the early identification of mental health challenges. Services coordinated by the school also are likely more accessible to the student and his or her family in terms of proximity and expense (Catron, Harris, \& Weiss, 1998). Furthermore, schools often have built-in networks of professionals (e.g., teachers, school psychologists, counsellors, resource teachers, etc.) and therefore may have greater ability to connect and coordinate with community support services (Eber et al., 2002). Eber et al. (2002) also found that when wraparound supports are provided in a school as a part of a PBIS framework, they may: (a) enhance parents' willingness to engage in the wraparound process, (b) facilitate the involvement of natural, community-based supports, (c) provide a continuum of behaviour support, and (d) support early intervention. Note, however that this research was conducted in the United States; research about the implementation of PBIS in Canadian schools is comparatively limited and has not involved the incorporation of what would be regarded as high-fidelity wraparound (McIntosh, Moniz, Kraft, Golby, \& SteinwandDeschambeault, 2014). While schools may mitigate some of the challenges associated with collaboration and service provision, a particular model of school - referred to as a full-service community school - may be best equipped to deliver highly integrated support for children and youth with mental health disorders and for their families through the implementation of wraparound approach.

\section{Community Schools in Manitoba, Canada}

In Manitoba, designated community schools are characterized as centres of inclusion that build collaborative partnerships and provide integrated support including but not limited to health, mental health, early childhood, family services, recreation, and nutrition (The Community Schools Act, 2013). According to Dryfoos (2005), a pioneer in the community school movement in the United States,

Community schools are those that have been intentionally transformed into neighborhood hubs and that are open all the time to children and their families. In these buildings, a range of support services is provided by community agencies to help overcome the many barriers that schools face in producing successful students. (p. 7)

Community schools in Manitoba serve the same function, in that they are located in neighbourhoods where, historically, access to resources has been limited and the population is highly vulnerable (e.g., low socio-economic status, transient, involved with child welfare, and some of the lowest academic achievement in the province). In addition to fostering partnerships, community schools in Manitoba seek to engage and empower 
the local community by fostering community-based leadership (The Community Schools Act, 2013).

According to Miles, Brown, and the National Wraparound Implementation Working Group (2008) when identifying a site as suitable to lead the implementation of wraparound, "A good first step is to review what sort of groundwork your community or system has laid for wraparound thus far, and to identify areas of greatest strength or capacity as well as the areas of greatest need" (p. 17). Community schools may have both the greatest capacity to implement the wraparound approach, as well as the greatest need for support, and therefore may be an ideal context for the provision for wraparound support.

\section{Purpose}

The current article explores the experiences and perspectives of stakeholders in community schools as they relate to the practices used to support children and youth with mental health disorders and their families. Specifically, the article examines practices that may reflect the 10 guiding principles of the wraparound approach. The 10 guiding principles of the wraparound approach are described as the "starting point" of wraparound implementation (Bruns et al., 2008). Since the wraparound approach is in the emergent stage of implementation in the province of Manitoba, an examination of the presence of the guiding principles of the wraparound approach in community schools may help to inform its implementation. To that end, we conducted a qualitative multiplecase study of three community schools in the province of Manitoba.

\section{Significance}

While there is a significant amount of research regarding the implementation of the wraparound approach in the United States, the research base in Canada is limited (Wallace, Debicki, Vander Vennen, \& de Visch Eybergen, 2012). To date, no Canadian studies have examined the implementation of the wraparound approach in community schools or the readiness of community schools to lead the implementation of the wraparound approach. Research on the implementation of the wraparound approach in Canada has focused on mental health settings (Brown \& Loughlin, 2004), child welfare (Browne, Puente-Duran, Shlonsky, Thabane, \& Verticchio, 2016; Wallace et al., 2012), primary care (Olibris et al., 2017), and youth justice contexts (Smith-Moncrieffe, 2014). The present findings contribute to the research base on wraparound by demonstrating the potential for inclusive environments like full-service community schools to incorporate wraparound planning as a part of the continuum of supports they provide.

\section{Theoretical Framework}

This study is rooted in a social constructivist epistemology. Through this lens, reality and facts are understood as a process of social construction (Skrtic, 1995). By implication, knowledge is acquired through social and experimental understanding and deduction. In short, information and knowledge are obtained through the meanings held by an individual or a group in regard to a particular experience. Given this theoretical 
foundation, a qualitative research methodology was employed to better understand the experiences and perspectives of the participants.

Another purpose of this study is to give value to the voices, feelings, actions, and meanings of the participants (Denzin, 1989). The data we collected from the lived experiences and personal perspectives of the participants were coded and analyzed through the framework of the 10 guiding principles of the wraparound approach. According to Crabtree and Miller (1992), this use of "prefigured codes" from the literature or from a theoretical model is consistent with qualitative research.

\section{Methods}

We used a qualitative, multiple-case study of three community schools in order to provide the participants with the opportunity to share their first-hand experiences in community schools and to allow for an in-depth understanding of each case.

Recruitment. Purposeful sampling was used to identify five school divisions in the province of Manitoba that had a minimum of one community school designated by the Community Schools Program. From the five school divisions that were contacted, three school divisions were selected to participate based on the order in which the superintendents responded to the request to conduct research. Each school division had one community school, and the community school was assessed to determine whether it met the following criteria: (a) designation as a community school for a minimum of five years by the Community Schools Program; (b) the existence of a community school council or an inclusive group of decision makers to lead the community school; (c) the existence of a community school plan with a focus on learning, integrated services, parent and community partnerships, and community development; and (d) the provision of support for students with mental health disorders according to Manitoba Education's funding criteria (Manitoba Education and Training, 2018). The three community schools in this study are identified as School A, B, and C and represent suburban, urban, and rural communities respectively.

School A. School A is a kindergarten-to-Grade-8 school located in a suburban setting with a student population of approximately 160 . Greater than $50 \%$ of the students who attend School A have self-identified as First Nations, Métis, or Inuit (FNMI). Even though School A is located in a suburban setting, the local community is considered a high-poverty neighbourhood, with low rates of high school completion, high rates of unemployment, and addictions. A majority of the students who attend School A reside in subsidized government housing, which is located across a large field from the community school. In spite of the fact that School A is located in a suburban neighbourhood, the neighbourhood is geographically isolated from local resources and public transportation. Many of the families who reside in this subsidized housing complex previously lived in the inner city and moved to the suburbs when a government housing unit became available, with the hope of having a better quality of life. Regrettably, many of the social challenges that exist in the inner city also exist in the pocket of government housing in this suburban area. The role of School A has been central in helping to overcome the challenges experienced by the students and families in this community. School A has been actively involved in community mobilization and in the development of many local 
partnerships - with a local community resource centre, several businesses, and postsecondary institutions. Given these partnerships, School A has been able to provide broad-based support (e.g., early childhood development initiatives, parenting and family support, athletics and recreation, nutrition support, mentorship, and connections to postsecondary education).

School B. School B is a kindergarten-to-Grade-5 school located in an urban setting with a student population of approximately 150 . At School B, greater than $50 \%$ of the students have self-identified as FNMI, and there is a growing immigrant population that comprises $30 \%$ of the student population. School B also is located in a high-poverty neighbourhood, with low rates of high school completion, and high rates of unemployment, and addictions. In spite of being located in the inner city, School B also is characterized as an isolated community. It is located adjacent to major railway lines that divide the neighbourhood and make it difficult to access much needed resources including public transportation and affordable food.

School B has developed a strong partnership with a local multidisciplinary community health provider, several charitable organizations, and local businesses. These partnerships have been essential in expanding the support that the school provides (e.g., early childhood programming, parenting support, mental health services, nutritional guidance, community gardens, cultural programs, and recreational opportunities) and have contributed to the revitalization of this community.

School C. School C is a kindergarten-to-Grade-12 school located in a remote, rural setting with a student population of approximately 140. Approximately $85 \%$ of the students have self-identified FNMI, and greater than half of the students are in some form of care (either through a child welfare agency or with relatives). The community has experienced a steadily declining population since service by the Canadian Pacific Railway ended to the community in the 1960s and a local mining operation shut down. This community also has high rates of poverty, unemployment, addictions, and low rates of high school completion. Given the declining population, several schools in neighbouring communities have closed. There is no grocery store, no gas station, no cellular telephone service, and most residents do not have reliable transportation. Affordable food and gas are located several hours away. School $\mathrm{C}$ is the heart of the community and plays a central role in connecting members of the community to local resources. In an attempt to reduce this isolation and foster a sense of community, School $\mathrm{C}$ has forged partnerships in the local area with the municipal government and its related government departments, but relies most heavily on local residents to provide a broad range of programming (e.g., early childhood support, summer programming, recreational opportunities, nutritional support, as well as cultural and arts programs).

Participants. There were 15 participants in this study, among them principals, teachers, a counselor, community school connectors, parents, and partnering services in community schools. Throughout the article, they are referred to by their role. Six participants from School A were interviewed: the school principal, a school counsellor, the community school connector, a parent, and two partnering service providers from a local community resource centre. Five participants from School B were interviewed: the school principal, a Grade 1 teacher who also was the literacy support teacher, the 
community school connector, a parent who also had a part-time job as a community school connector, and a partnering service provider from local multidisciplinary community health provider. Four participants were interviewed from School C: the school principal, a high school teacher who also served as the acting principal in the principal's absence, the community school connector, and a parent who also was employed as an educational assistant at the community school.

Data collection. Over a 3-month period, in-depth, semi-structured interviews were digitally recorded and transcribed. Two of the interviews (ranging from 30 to 115 minutes) were conducted in community-based settings, including a local community resource centre, and a multidisciplinary community health centre, which provided insight into the resources in the local areas and the partnerships that existed.

The first round of interviews involved all participants; all principals were interviewed for a second time. The topics explored during the interviews included: (a) experiences related to children and youth with mental health disorders, (b) experiences with collaboration, (c) decision making, (d) individualized planning and provision of support, and (e) attitudes toward governance, programming, resources, funding and overall support for children and youth with mental health disorders and their families. The participants also were encouraged to provide additional information about issues that were relevant to them. A comprehensive member-checking process was used to allow participants to evaluate the fairness and validity of the interview responses (Creswell \& Miller, 2000). While the participants were not directly asked about the community schools' adherence to the 10 guiding principles of the wraparound approach, the participants' responses were analyzed to identify evidence of these guiding principles.

Data analysis. We conducted both a within-case and a cross-case analysis. To prepare for these we summarized the data in a case study format and incorporated "thick descriptions" of each case (Merriam, 1998). Using the ten guiding principles of the wraparound approach (Bruns et al., 2008), we analyzed participant responses to determine the extent to which the principles of the wraparound approach were described as being evident in schools A, B, and C. This involved using an a priori content analysis (Crabtree \& Miller, 1992), and sorting and analyzing data under the pre-existing categories of the 10 guiding principles of the wraparound approach.

\section{Findings and Discussion}

In this section we present evidence of the 10 guiding principles of the wraparound approach within the cases, and we examine the variability across the cases. The section also provides a discussion about how the wraparound approach may build upon existing structures in community schools and strengthen planning practices for children, youth, and families.

\section{Family Voice and Choice}

The wraparound approach seeks to empower individuals who have been disempowered and to ensure that the first principle of "family's voice and choice" drives the provision of wraparound support (Bruns et al., 2008). According to Blank, Melaville, 
and Shaw (2003) unlike traditional schools, community schools regard families from diverse backgrounds as assets, and therefore may be more likely to value their input and enlist their meaningful participation. All of the participants in this study described how the staff, students, administrators, and partnering service providers from their community schools valued parental contributions and actively sought their input: (a) as volunteers, (b) in leadership roles on parent councils, (c) as employees, (d) in teaching capacities to share their skills, and (e) to participate in key decisions related to the provision of support for their children. Valuing parents' knowledge and lived experience translated into concrete actions in all of the community schools. In particular, given the remote, rural location of School C, parents were described as central to all operations of the community school. The community school connector said, "We all wear a lot of hats around here. We're a parent, we're on the gardening committee, and we're an EA [educational assistant]." A parent who was a new Canadian at School B described how she was enlisted to volunteer in the community school and ultimately was hired to work in the school. A parent at School A described how her input was valued when critical decisions were made about support for her child. To illustrate,

My daughter was really connecting with her EA, and it took almost the whole year, and I was finally feeling like things were working and then the year was over.... I said to the teachers, "She needs the same EA." They listened. It wasn't all about the rules and things like that, it was about what was best for her.

In this study the data indicates that participants felt a strong need to value the voices and choices of the families they were serving. This finding is consistent with the first principle of wraparound in which the child or youth and his or her family, along with the family's perspectives, goals, and values, are seen as central to the process. There were many examples in which the participants shared belief systems and practices were consistent with what Moll, Amanti, Neff and González (2005) described as regarding parents as "funds of knowledge ... which refer to these historically accumulated and culturally developed bodies of knowledge and skills essential for household or individual functioning and well-being" (p. 73). When parents are regarded as "funds of knowledge," as opposed to viewed through a deficit lens, respect for their voice and choice may be more likely to occur.

\section{Natural Support}

Another finding from this study that is compatible with the wraparound approach is the presence of natural supports in the community schools. Natural support includes interpersonal supports from a family's local network of individuals with whom they have relationships and who are invested in their well-being (Bruns et al., 2008). Research in adherence to the guiding principles of wraparound indicates that the inclusion of natural supports on wraparound teams is often difficult to achieve, as parents involved in the wraparound approach may become isolated from interpersonal connections (Bruns, 2010; Epstein et al., 2003) and may experience feelings of shame due to their personal challenges (Dalder, 2006). All three of the community schools that we studied demonstrated some evidence of natural support being used. In fact, these supports were infused within the community school through the daily presence of many natural helpers. These helpers included elders, grandparents, and other members of the community (e.g., 
a local farmer and chef who provided free cooking classes, a parent who taught Indigenous beading).

However, in Schools B and C, the most poignant example of natural support was provided by the community school connectors. Community school connectors are employed by community schools and play a direct role in building partnerships as they serve to build bridges between the community, the school, and other resources (Blank, 2005; Blank et al., 2003; Campbell-Allan, Shah, Sullenden, \& Zazore, 2009). In Schools B and $\mathrm{C}$, the community school connectors were lifelong residents of the local community and were described as having trusting relationships with their "neighbours." The principal of School B described how he believed that community school connectors should be hired based on their ability to personally connect with the local community. He said,

The role ... of the community connector is that person is a bridge between the community and the school. And the school, we're seen as "we're the school" with our university degrees.... And the community is not ... So to have someone come in as a community connector who has degrees ...that would just keep the barrier there.

Given their relatability to the community, the community school connectors at Schools B and C were sought out to provide both moral support and assistance with service acquisition. A parent and educational assistant at School $\mathrm{C}$ described how the community school connector was trusted by the community. She said, "Families feel safe to go to her." A community school connector at School B described how living in the local community for her entire life provided her with a unique insight into the challenges in the community (e.g., poverty, addictions); and because of her personal connections within the community, people sought her out in times of need. The community school connector at School C described how local residents would come to her home outside of school hours asking for support:

For example, this family was in town, they knocked on my door because, you know, who knows what's happening with their mom at home? She's trying, but she just doesn't have the support that she needs from the system.... I don't turn off the community connector switch, you know what I mean?

In contrast, the principal of School A made it a priority that the community school connector should have educational credentials to support initiatives at the community school. The principal of School A said,

[The community school connector's] got a degree in community health. We have a focus on connecting through nutrition, and I needed a person with skills who could make nutrition and healthy living a part of what we do, and do it well.

The community school connector at School A was a recent university graduate, and she was not a lifelong resident of the local community. While she provided much support to the students in the school (e.g., nutrition, social skills development, athletic programming), her relationship with families and the community differed from that of the other community school connectors. More specifically, community members did not seek her out for the kind of personal support that the other community school connectors described. The community school connectors, who were trusted residents of the community, provided assistance that could be described as similar to the support provided by peer support partners. In some jurisdictions, peer support partners are 
provided to parents involved in the wraparound process, not because they have formal training, but rather because they have similar lived experiences to those of the parents they support. Based on their background peer support partners are able to provide moral support and assistance in accessing both informal and formal supports (Osher \& Penn, 2010). The utilization of trusted members of the local community as community school connectors aligns closely with the third guiding principle of wraparound, which is to utilize the natural supports that exist within community networks, as they are likely sustainable in the long term. Given their personal connections to some of the most vulnerable children, youth, and families, the community school connectors in Schools B and $\mathrm{C}$ may hold much potential to support the implementation of wraparound, given they already function as strong sources of natural support.

\title{
Team-Based Collaboration
}

Team-based collaboration is another finding that was present within the community schools and aligns with the wraparound approach. Team-based collaboration refers to the existence of partnerships and the joint work that occurs within and between groups (Bruns et al., 2008). Community schools are typically comprised of extensive networks of community partnerships (Raffo \& Dyson, 2007). In a comprehensive review of the literature on community schools, Heers, Van Klaveren, Groot, and Maassen van den Brink (2016) found that community schools had established broad-based support that was unique to the communities they served and, in some instances, included up to 20 different stakeholder groups.

Other related research on community schools has not only highlighted the existence of collaborative partnerships, but also has identified the invaluable leadership role that community schools played in fostering the development of collaborative partnerships in the local community (Henig, Riehl, Houston, Rebell, \& Wolff, 2016). A teacher and acting principal at School $\mathrm{C}$ described how collaborative teamwork was central at a community school and involved multiple stakeholders. He said,

\begin{abstract}
You need to be part of the planning team. You need to work with the staff, community partnerships, social services, and people up in the department, the community connector, the rec commission for use of facilities, and the municipality. You have to try and make connections, for example with the local constable and RCMP [Royal Canadian Mounted Police], too. It's trying to get more people, staff, to have a shared vision.
\end{abstract}

A partnering service provider from a local community health organization at School B described the kind of collaborative teamwork that also occurred when highly individualized planning was required for a specific child or youth. She said,

[The principal] will just call me up and ask for my help. We collaborate around plans and kids that they are really concerned about. He invites everyone to the table and we put our heads together. It's almost a little bit of wraparound, which I really like.

The existence of partnerships in all of the community schools that were studied may set the stage for the implementation of the wraparound approach. These partnerships, along with a climate that fostered collaboration and interdependence, may serve as foundational for wraparound implementation. This finding is consistent with the second 
and fourth principles of wraparound. Under the wraparound approach, team members collaborate with one another and include community members when developing, implementing, monitoring, and evaluating a child or youth's wraparound plan. These findings of existing collaborative networks indicate that community schools already possess a key element for implementing wraparound. Due to this collaboration, it is not surprising that in this study, evidence supporting the use of community-based supports also were found.

\section{Community-Based Support}

Community-based support refers to support that is available within the local community and that promotes authentic participation in community life (Bruns et al., 2008). The availability of services in the local community has been found not only to improve access, but also to promote service utilization (Catron et al., 1998; Harbin et al., 2000). Bruns et al. (2004) found that the provision of community-based supports provided families who were participating in wraparound with a feeling of security in knowing that once formal wraparound ended, they would be surrounded by supports in their local community.

According to Eber et al. (2002), the location of schools naturally enables the provision of community-based supports. A principal at School A described how the proximity of the school in the local community was essential in the provision of support. He said,

If they're having trouble with housing, if they're having trouble finding a doctor, if they're having trouble with [Family Services], if they're having issues, any human services related issues. Well, they come to us first, because where else are they going to go? This is what they see every day, and it's our job to help.

In all of the community schools a lack of transportation was identified as a barrier to the receipt of support, which led to an increased need for community-based support. A teacher at School B described how a lack of transportation, combined with concern about the stigma associated with accessing support in settings outside of the school, had prevented some families from seeking help . The same teacher at School B provided an example of a student who had benefited from the provision of school-based mental health support. She shared, "Our partnership with [a mental health provider] has been huge for this student and his family. That is what has allowed us to make gains with this student. It wouldn't have happened if it wasn't here at the school."

While all of the community schools valued collaboration and developed partnerships to facilitate the provision of community-based support, the remote location of School $\mathrm{C}$ created ongoing challenges with respect to the availability of community-based support. Hiring more specialized positions like resource teachers, counsellors, and social workers was described as extremely challenging. The community school connector in School C said, "Teachers coming and going are a pretty common thing ... I was reading a report from 2006. That year they had 100\% turnover." The principal of School C described the difficulty with maintaining a social worker in the local community. Given the high rates of children in care, he regarded this as a crucial community-based support. He said, "One [social worker] came in, she was here for a while. She eventually left and then we had another one ... and she left in a matter of days." In a community without a local doctor, 
and with a public health nurse who is available only once per week, the responsibility to provide support largely resided with the local residents.

In this study, the provision of community-based supports, while desired in all settings, was achieved to a greater degree in Schools A and B, given their location within a major metropolitan centre. This finding is compatible with the fourth principle of the wraparound approach. Under wraparound, community-based services are integrated into a child's or youth's wraparound plan to enhance the inclusiveness, responsiveness, and accessibility to interventions, activities, and supports. While the participants at School C attempted to compensate for the absence of many community-based services by expanding the roles of local, natural support providers, the scope of support was limited. In this setting the adoption of the wraparound approach, while not a substitute for access to community-based resources, may provide a structured planning process that enables the more effective use of supports that are available.

\section{Culturally Competent}

The cultural competence of community school members also corresponds with the wraparound approach. The term culturally competent refers to the ability of service providers to respect and value the culture, language, beliefs, and practices of the diverse population they are serving (Bruns et al., 2008). In this study, the community schools served populations that predominantly included FNMI peoples. Respecting this fact, the participants acknowledged the intergenerational harms of the residential school system experienced by many members of the local community (Battiste \& Mclean, 2005; Brown, Rodger, \& Fraehlich, 2009), and the impact it continues to have on families' willingness to trust and to engage with the school. Additionally, the province of Manitoba has one of the highest rates of children in care in Canada (General Child \& Family Services Authority, 2014). As a result, the participants recognized that some of the population served by the community schools have had negative experiences with the child welfare system and because of this were cautious in their involvement with this service and others.

Jacobson and Blank (2011) described community schools as having strong potential to include those who have been marginalized for reasons of poverty, race, discrimination, and lack of support. A parent and educational assistant at School $\mathrm{C}$ described the feelings expressed by many parents in the local community. She emphasized the need for the community school to forge partnerships with families, saying,

They're nervous about someone coming in and telling them how to do something. And a lot of times they have to deal with [child welfare], or somebody's always telling them how to raise their family, and it's not their traditional ways.

As a result of these experiences and others, Whitley (2014) emphasized the need to focus on building positive and supportive interpersonal relationships with FNMI students and families. In fact, all of the participants described their personal responsibility toward building relationships, based on trust and mutual respect, with members from the local community. A teacher at School $\mathrm{C}$ shared the importance of repeatedly extending invitations to all community members; in the hopes that they might feel safe coming to the school and speaking directly with teachers about their 
children. A teacher and acting principal, who had taught at School C for seven years, described how the school was breaking down some of the barriers that had previously prevented parental engagement. He said,

I think that we've seen an improvement with parents wanting to come to the school. Because the attitude has been ... "I went to school, I hated it and I don't ever want to go back." ... They now see something different, they see it as a positive thing for their child to be in school.

Another way that the community schools established trusting, reciprocal relationships with families was by infusing Indigenous culture into the community school, led by Indigenous members of the local community. One teacher mentioned a local elder who had led a drumming group at School B. School B also hosts an annual Métis family fun night to celebrate the Métis culture that includes traditional dancing, art, and foods. Some of the other volunteers included a person who provided fiddle lessons, a social worker who taught beading, and other community members who volunteered to prepare and serve traditional Indigenous foods at the school's breakfast and hot lunch programs. The infusion of Indigenous culture was not limited to cultural activities; it included the use of culturally relevant pedagogy and curriculum. For example, at School C, a Grade 12 course entitled Current Topics in First Nations, Metis and Inuit studies: A Foundation for Implementation (Manitoba Education, 2011) was offered. As a second example, School A provided an early childhood program for parents and children from birth to age five that was taught by Indigenous early childhood educators. The program utilized First Nations teachings and included the exploration of Indigenous rhymes, songs, music, dance, art, and literature.

This respect for cultural diversity among community school members corresponds with the sixth wraparound principle of cultural competence. When community school members act in culturally responsive ways, they value families' heritage, beliefs, and practices and regard their cultural identity as a source of strength. The evidence of cultural competence in the community schools that we studied demonstrates the readiness of community schools to implement a planning processes like wraparound, which embraces culturally relevant practices in the development of a plans of support.

\section{Individualized, Strength-Based Support}

By valuing the culture of the children, youth, and families that they serve, community schools are able to provide individualized and strength-based support to families in valuable and respectful ways. Providing individualized and strength-based support during the wraparound process involves tailoring the wraparound plan to meet the unique needs of children, youth, and families. These plans purposefully build upon the strengths possessed by the population served (Bruns et al., 2008). All of the community schools in this study utilized an individualized education planning (IEP) process and an individualized behaviour intervention planning (BIP) process that were strength based. Eber et al. (2002) argued that the wraparound process is a natural extension of the highly individualized, structured planning and support that is already provided within schools. The principal of School A described the individualized nature of planning and the need to consider every student's "individual story," in the provision of 
support. He stated, "Let what kids need drive what we do." A teacher at School B described the inclusive nature of the school and provided specific examples of the highly individualized support that they provided. She shared,

We really practice inclusion. It's okay to need something different ... We provide whatever the students need. It might be calming activities and alternate spaces in order to help them to self-regulate. We provide breaks. We feed students regularly. If they need to sleep, we provide a place for that, too. We offer special projects, like we're doing a skate board project to engage the students who need it. The gym is also always open, too. It's just what we do.

The individualized planning processes that were utilized within the community schools also showed evidence of being strength based. The community school connector at School A described how some students who had been "kicked out" of other schools were sent to the community school. As a result of this, the school staff at the community school had purposefully sought to capitalize upon their strengths and provide individualized support. This allowed these students to thrive academically and behaviourally. To illustrate, "We've also had students in a couple of cases that were sent here from other schools because their behaviour was so 'bad' that they sent them to us ... and she is doing amazing here."

In this study, there was evidence in support of the highly individualized nature of planning and a willingness to build upon the strengths of the population served by the community schools. These practices reflect the seventh and eighth guiding principles of the wraparound approach as outlined in Table 1. While the approach to the provision of support in the community schools utilized a structured IEP and BIP process, the nature of support provided was flexible and responsive to individual needs and could be characterized as including "non-traditional" support, which is a hallmark of wraparound planning. The structures in place in community schools, which support the development and implementation of highly individualized plans including multiple stakeholders, is another indicator of readiness to implement the wraparound approach and to provide unconditional support.

While processes related to individualized planning were in place in all settings, case management roles and responsibilities in the IEP and BIP were less formalized. In School $\mathrm{A}$ and School B, the principal was described as leading most of the individualized planning for students with complex mental health needs; and in School C, the community school connector was described as taking on this important role. Scott et al. (2005) argued that when planning for students with complex mental health needs in schools, specialized skills in facilitation are required. In the community school settings that we studied, it may be beneficial to implement the wraparound approach, as the provision of wraparound support incorporates a formal case management model through the use of wraparound facilitators. Wraparound facilitators may be existing school staff (e.g., principals, social workers, school psychologists, counsellors, or resource teachers) who receive training and ongoing coaching in wraparound and who are responsible for ensuring adherence to the wraparound practice model (Bruns \& Walker, 2010). According to Eber et al. (2011) the training wraparound facilitators receive is comprehensive and "commensurate with the intricacy of the intervention required for this population" (p. 787). Furthermore, research has found that when trained wraparound 
facilitators lead individualized planning, team effectiveness is increased (VanDenBerg \& Grealish, 1998; VanDenBerg \& Rast, 2003). In this regard, the structures in place in community schools that support individualized planning may be strengthened by the incorporation of the wraparound approach, and more specifically, the use of trained wraparound facilitators to guide the planning process.

\section{Unconditional}

This ninth principle in wraparound refers to the unconditional support provided to children, youth, and families. Under this principle, rejection does not occur and support is provided during setbacks and challenges (Bruns et al., 2008). Often parents of children with mental health disorders feel negatively judged by the professionals charged with supporting them, which may create a reluctance to engage in planning processes (Painter, Allen, \& Perry, 2011). Furthermore, zero-tolerance policies and suspensions for behaviour incidents have been found to further alienate parents from the school and to interfere with collaborative planning (Eber et al., 2002). However, in the wraparound approach a "no blame, no shame" attitude is embraced by the wraparound team (Debicki \& Wrap Canada, 2012, p. 8). Unconditional care was evident in all of the community schools that were studied. The principal of School A described his unconditional commitment to all students and families. He said, "Oh, I give lots of chances. How many chances? ...Well, as many as they need. If I run out of chances, I've got a box full more in the trunk. It's the same with families."

The principal of School B shared a similar philosophy of unconditional care. He said, "There's nothing that could walk through that door that we can't deal with." A counsellor at School A described the approach the school had taken to tardiness and attendance, which reflected the "no blame, no shame" philosophy. She said, "We just say how happy we that they are here, and then we ... add them to our walking school bus. We don't embarrass them or blame them. If we did that, we would never see them."

The participants in community schools did not regard "giving up" on children, youth, and families as an option. This unconditional care reflects the ninth guiding principle of the wraparound approach and is another indicator of the readiness of community schools to implement the wraparound approach.

\section{Outcome-Based}

In addition to the utilization of person-centred approaches, the community schools that were studied, to varying degrees measured the outcomes of the support that they provided. Wraparound is an outcome-based process, which means that specific objectives are set and monitored over time. Progress toward the achievement of the stated objectives also are measured (Bruns et al., 2008). The measurement of outcomes is an essential component of the wraparound process and must be supported by the host environment (Bruns \& Walker, 2010; Walker, 2008; Walker, Koroloff, \& Schutte, 2003). In all of the community schools that we studied, there was some evidence of the measurement of the overall support provided by the community schools through the collection of attendance data. Additionally, there was some evidence of the measurement of outcomes in individualized plans. While the measurement of outcomes was described at all schools, 
School B had the strongest focus on the use of outcome-based measures as a part of its overall planning processes.

The collection of attendance data demonstrates the openness of the community schools in this study to engage in evaluation, and a desire to ensure that the supports that are provided are responsive to the needs in the community. The community school connector at School $\mathrm{C}$ described how she monitored the attendance of parents and children at the early childhood programs that she offered and found not only improved attendance, but also an expansion of the target audience. She said, "So parents come in here [to the family room], and it's not just with their toddlers any more. They come in with their infants now, too, ... and we were having up to six kids attending with their parents." Similarly, School A and School B collected attendance data for the programs they provided, as well as for the students supported by a walking school bus initiative. Related research on school attendance has found that students have higher levels of attendance when connections between the home, school, and community exist (Epstein \& Sheldon, 2002); and students are more likely to participate in activities and feel a sense of connection to the school when their parents also attend activities at the school (Thompson, Iachan, Overpeck, Ross, \& Gross, 2006). These findings underscore the value of attendance data as an indicator of student and parent engagement with the school.

While all schools collected attendance data, reliance on additional outcome-based measures varied across settings. In this regard, the principal's attitude about the importance of data seemed to determine the degree to which outcome-based measures were prioritized in the community schools that were studied. For example, the principal of School B highly valued the formal measurement of progress. He said, "I just love Excel.... We keep track. 'Did they grow?' 'Is there movement, or are they static?'” However, in School A and School $\mathrm{C}$ there was a greater reliance on observational and anecdotal evidence and on the "belief" that there was growth occurring. In reference to the impact of community school support, the principal of School A said, "So does all of this make a difference? It has to. I have to believe that." Similarly, the principal of School C said,

I don't know if they [the programs] are bringing about benefits because I've got nothing to compare it to. But I do know there's a difference here compared to other schools, and it's more of a community than any other school.

The existence of planning processes and accountability structures that mirror the wraparound approach may allow for wraparound planning to be easily embedded in the planning practices, particularly in settings like School B, which prioritize the use of data to drive decision making. However, settings like School A and School C also may benefit from incorporating the wraparound approach into its existing planning practices, as it provides an articulated practice model and structures that support formalized measurement, which also may enhance the use of measurement in those settings.

\section{Summary of Findings}

Our analysis showed that participants' responses (a) reflect the guiding principles of the wraparound approach, and (b) provide evidence of the community schools' readiness to implement the wraparound approach. We found some variability across cases with respect to evidence of the 10 guiding principles, including: (a) the degree to which community 
school connectors were sources of natural support, (b) the availability of community-based resources in remote settings, (c) formalized case management processes, and (d) the use of outcome-based measures. The implementation of the wraparound approach as a practice model may build upon the many existing structures in community schools that reflect the 10 guiding principles of wraparound, and may serve to strengthen areas where there may be less alignment with these principles. For example, the adoption of the wraparound approach may provide a structure for the utilization of peer support partners as sources of natural support for children, youth, and families. This could become a formal role for community school connectors, or perhaps a role for other trusted residents in local communities. While wraparound as a planning tool cannot create community-based resources, it may provide a planning structure that promotes the more efficient and effective use of existing resources, particularly in remote communities where access to services is limited. Given that the wraparound approach, when fully implemented, involves a formalized case management process and the use of trained wraparound facilitators to guide planning for vulnerable children, youth, and families, it may ensure more effective planning and closer adherence to evidence-based planning processes. Furthermore, through its emphasis on outcome-based measurement, wraparound may be easily embedded into existing planning structures where the measurement of outcomes is already a focus, and it may provide a process for the measurement of outcomes in settings where outcome-based measurements are not yet well established.

While this study examined community schools in Manitoba, these findings may be relevant within a broader context. In Canada, community schools are found in Nova Scotia, New Brunswick, Prince Edward Island, Yukon, Quebec, Ontario, British Columbia, Saskatchewan, and Manitoba (respectively, Nova Scotia Department of Education, 2015; Government of New Brunswick, 2012; Prince Edward Island Department of Workforce and Advanced Learning,; 2016; Yukon Health and Social Services, 2015; Government of Quebec, 2012; Toronto District School Board, 2015; British Columbia Ministry of Education, 2012; Tymchak \& the Saskatchewan Instructional Development Unit, 2001; The Community Schools Act, 2013). Internationally, there are versions of community schools that exist in many countries around the world (Heers et al., 2016). In Canada and around the world, the community school model varies to reflect the cultural and social climate of the institution and needs of the community (Heers et al., 2016). While the community schools internationally may differ in approach, there are many commonalities. For one, proponents of community schools agree that educating children requires a holistic approach that may involve going above and beyond the traditional school model (Heers et al., 2016). Second, positive partnerships and collaboration with people and organizations within the community contribute to a supportive developmental environment. Third, the school is viewed as hub in which the provision and coordination of school and community services occurs for children and their families (Zigler, Finn-Stevenson, \& Stern, 1997). Due to these shared pragmatic and philosophical underpinnings, the findings in this study may contribute to the broader literature on the wraparound approach and community schools in Canada and internationally. While further research is required, community schools worldwide may already have the capacity to implement the wraparound approach, and as a result, may 
overcome the barriers to the provision of integrated support for children and youth with mental health disorders and their families.

\section{Limitations and Areas for Future Study}

There are at least four limitations in this study. The first three limitations generally apply to most qualitative research designs. First, while this was a multi-case study, which allowed for an in-depth exploration of each case, the sample size is still too small to make the results generalizable. Consequently, the findings may not reflect the majority of community school stakeholders' perspectives regarding community schools and evidence of the guiding principles of the wraparound approach; and they may not speak to the readiness of other community schools to implement wraparound. Second, the participants in this study were not chosen randomly. Although this study used a small and selective sample from three jurisdictions, efforts were made to ensure that the participants' perspectives were captured as accurately as possible. The third limitation is researcher bias in a qualitative design. However, triangulation (i.e., data collected from different participants in different schools) as well as member checking were used to ensure the trustworthiness of the results. Selection bias, researcher bias, and theoretical sensitivity of the researcher are internal threats to validity that should be noted. The Hawthorne effect (e.g., the participants were aware that they were participating in this research, which may have affected how they participate) is a threat to the external validity of this research. Finally, it could be considered a limitation of this study that the determination of evidence of the 10 guiding principles of the wraparound approach as defined by Bruns et al. (2008) relied upon the participants' perceptions of their experiences in community schools and therefore cannot be regarded as a definitive account of all experiences in community schools. While this exploratory qualitative study was small in scale and cannot be generalized, it contributes to research on wraparound by identifying the alignment of the beliefs and practices in community schools with the 10 guiding principles of the wraparound approach. It further provides evidence of existing collaborative partnerships and access to broad-based support, which together may set the stage for the implementation of this integrated approach.

However, several areas warrant further study as a result of this research. For example, the administration of the Community Supports for Wraparound Inventory (Walker \& Sanders, 2011) may provide further information about the implementation context for wraparound. This assessment would identify other contextual variables that must be strengthened in order to support the implementation of the wraparound approach in an environment like a community school. Future research may involve exploring the formal designation of community school connectors as peer support partners for parents participating in the wraparound process. There was much evidence in this study that the community school connectors were sources of natural support and played parallel roles to that of a peer support partner, and therefore, may provide valuable support if they were designated to serve in this capacity. Finally, training school staff as wraparound facilitators to guide the implementation of the wraparound process in the context of a community school may provide valuable information about the role they may play in ensuring adherence to the wraparound practice model and in optimizing support for children, youth, and families. 


\section{Conclusions}

Identifying an environment like community schools that reflects the 10 guiding principles of the wraparound approach and possess existing broad-based collaborative partnerships at the local level may be the first step in developing a comprehensive plan to guide the implementation of the wraparound approach. Evidence of the 10 guiding principles of the wraparound approach and collaborative partnerships in the community schools that were studied may indicate that community schools hold much promise as sites well equipped to lead the implementation of the wraparound approach. Human resource development and capacity building may be a worthwhile investment, in order to provide formal training in the wraparound approach for stakeholders in community schools. The implementation of the wraparound approach may build upon community schools' existing collaborative, person-and family-centred planning and enhanced service provision for children and youth with mental health disorders and for their families (Walker et al., 2003; Walker \& Sanders, 2011).

\section{References}

Adams, N., Daniels, A., \& Compagni, A. (2009). International pathways to mental health transformation. International Journal of Mental Health, 38(1), 30-45.

Battiste, M., \& McLean, S. (2005). State of First Nations learning. Saskatoon, SK: Aboriginal Education Research Centre. Retrieved from http://www.ccl-cca.ca/pdfs/AbLKC /StateOfFirstNationsLearning.pdf

Blank, M. J. (2005). Reaching out to create a movement. In J. G. Dryfoos, J. Quinn, \& C. Barkin (Eds.), Community schools in action (pp. 243-258). New York, NY: Oxford University Press.

Blank, M. J., Melaville, A., \& Shah, B. P. (2003). Making the difference: Research and practice in community schools. Coalition for Community Schools: Washington, DC: 2003.

British Columbia Ministry of Education. (2012). Neighbourhood learning centres [Webpage]. Retrieved on August 31, 2018 from http://www2.gov.bc.ca/gov/topic.page?id $=817$ C919AB33D42D5B89A0714F5FCE280

Brown, J., Rodger, S., \& Fraehlich, C. (2009). School experiences of Aboriginal youth in the inner city. Ottawa, ON: Canada Council on Learning. Retrieved from http://www.cclcca.ca/pdfs/FundedResearch/Brown-SchoolExperiencesFullReport.pdf

Brown, R. A., \& Loughlin, J. (2004). A cost satisfaction study of the wraparound process. Proceedings from the 16th Annual Research Conference: A System of Care for Children's Mental Health: Expanding the Research Base, Tampa, Florida, pp. 297-302.

Browne, D. T., Puente-Duran, S., Shlonsky, A., Thabane, L., \& Verticchio, D. (2016). A randomized trial of wraparound facilitation versus usual child protection services. Research on Social Work Practice, 26(2), 168-179.

Bruns, E. J. (2010). Wraparound Fidelity Index, version 4: Summary of relevant psychometrics, reliability, and validity studies. Seattle, WA: University of Washington, Division of Public Behavioral Health and Justice Policy.

Bruns, E. J., Rast, J., Peterson, C., Walker, J., \& Bosworth, J. (2006). Spreadsheets, service providers, and the statehouse: Using data and the wraparound process to reform systems for children and families. American Journal of Community Psychology, 38(3-4), 201-212. 
Bruns, E. J., Sather, A., Pullmann, M. D., \& Stambaugh, L. F. (2011). National trends in implementing wraparound: Results from the state wraparound survey. Journal of Child and Family Studies, 20(6), 726-735. doi:10.1007/s10826-011-9535-3

Bruns, E. J., \& Suter, J. C. (2010). Summary of the wraparound evidence base. In E. J. Bruns \& J. S. Walker (Eds.), Resource guide to wraparound. Online publication. Portland, OR: National Wraparound Initiative. Retrieved from https://nwi.pdx.edu/NWI-book/Chapters/Bruns-3.5(evidence-base).pdf

Bruns, E. J., Suter, J. C., Force, M. M., \& Burchard, J. D. (2005). Adherence to wraparound principles and association with outcomes. Journal of Child and Family Studies, 14(4), 521-534. doi:10.1007/s10826-005-7186-y

Bruns, E., \& Walker, J. S. (2010). The wraparound process: An overview of implementation essentials. In E. J. Bruns \& J. S. Walker (Eds.), Resource guide to wraparound. Online publication. Portland, OR: National Wraparound Initiative. Retrieved from https://nwi.pdx.edu/NWI-book/Chapters/Bruns-5a.2-(implementation-essentials).pdf

Bruns, E. J., Walker, J. S., Adams, J., Miles, P., Osher, T. W., Rast, J., ... National Wraparound Initative Advisory Group. (2004). Ten principles of the wraparound process. Portland, OR: National Wraparound Initiative.

Bruns, E. J., Walker, J. S., \& the National Wraparound Initiative Advisory Group. (2008). Ten principles of the wraparound process (Rev. ed.). In E. J. Bruns \& J. S. Walker (Eds.), Resource guide to wraparound. Online publication. Portland, OR: National Wraparound Initiative.

Burns, B., \& Goldman, S. (Eds.). (1999). Systems of care: Promising practices in wraparound for children with serious emotional disturbance and their families' mental health. (Vol. IV). Systems of care, promising practices in mental health, 1998 series. Washington, DC: Center for Effective Collaboration and Practice, American Institutes for Research.

Campbell-Allan, R., Shah, M., Sullenden, R., \& Zazore, R. (2009). Full-service schools: Policy review and recommendations. Informally published on a file sharing service. Retrieved from http://a100educationalpolicy.pbworks.com/f/Full+Service+Schools+complete+paperZ.pdf

Carney, M. M., \& Buttell, F. (2003). Reducing juvenile recidivism: Evaluating the wraparound services model. Research on Social Work Practice, 13(5), 551-568. doi:10.1177/1049731503253364

Catron, T., Harris, V. S., \& Weiss, B. (1998). Post-treatment results after 2 years of services in the Vanderbilt school-based counseling project. In M. H. Epstein, K. Kutash, \& A. Duchnowski (Eds.), Outcomes for children and youth with emotional and behavioral disorders and their families: Programs and evaluation best practices (pp. 653-656). Austin, TX: PRO-ED, Inc.

Chartier M., Brownell, M., MacWilliam L., Valdivia, J., Nie, Y., Ekuma, O., ... Kulbaba, C. (2016). The mental health of Manitoba's children. Winnipeg, MB: Manitoba Centre for Health Policy, Fall 2016. Retrieved from http://mchpappserv.cpe.umanitoba.ca/reference /MHKids_web_report.pdf

Clark, H. B., Lee, B., Prange, M. E., \& McDonald, B. A. (1996). Children lost within the foster care system: Can wraparound service strategies improve placement outcomes? Journal of Child and Family Studies, 5(1), 39-54. doi:10.1007/BF02234677

Clark, H. B., Prange, M. E., Lee, B., Stewart, E. S., McDonald, B. B., \& Boyd, L. A. (1998). An individualized wraparound process for children in foster care with emotional/behavioral disturbances: Follow-up findings and implications from a controlled study. In M. H. Epstein, K. Kutash, \& A. Duchnowski (Eds.), Outcomes for children and youth with emotional and behavioral disorders and their families: Programs and evaluation best practices (pp. 513542). Austin, TX: PRO-ED, Inc. 
The Community Schools Act, C.C.S.M. c. C168 (2013). Retrieved from https://web2.gov.mb.ca /laws/statutes/ccsm/_pdf.php?cap=c168

Conklin, C. (2008). Funding wraparound is much more than money. In E. J. Bruns \& J. S. Walker (Eds.), Resource guide to wraparound. Online publication. Portland, OR: National Wraparound Initiative. Retrieved from: https://nwi.pdx.edu/NWI-book/Chapters/Conklin5d.5-(funding-wrap).pdf

Crabtree, B., \& Miller, W. (1992). Doing qualitative research. Newbury Park, CA: Sage Publications.

Creswell, J. W., \& Miller, D. L. (2000). Determining validity in qualitative inquiry. Theory into Practice, 39(3), 124-130.

Dalder, G. (2006). Wraparound and natural supports: Common practice challenges and promising coaching solutions. Focal Point, 20(1), 26-28.

Debicki, A., \& Wrap Canada. (2012). An overview of the Canadian wraparound model and certification system. Hamilton, ON: Wrap Canada. Retrieved from http://www.wrapcanada.org /html/pdf/CanadianTrngManualOrientWrapSec2RJune6,2012.pdf

Denzin, N. (1989). Interpretive biography. Thousand Oaks, CA: Sage Publications.

Dryfoos, J. (2005). Full-service community schools: A strategy—not a program. New Directions for Youth Development, 107, 7-14.

Eber, L., Hyde, K., \& Suter, J. (2011). Integrating wraparound into a schoolwide system of positive behavior supports. Journal of Child and Family Studies, 20(6), 782-790.

Eber, L., Sugai, G. Smith, C., \& Scott, T. (2002). Wraparound and positive behavioural interventions and supports in the schools. Journal of Emotional and Behavioural Disorders, 10(3), 171-180.

Epstein, M. H., Nordness, P. D., Kutash, K., Duchnowski, A., Schrepf, S., Benner, G. J., \& Nelson, J. R. (2003). Assessing the wraparound process during family planning meetings. Journal of Behavioral Health Services \& Research, 30, 352-362.

Epstein, J. L., \& Sheldon, S. B. (2002). Present and accounted for: Improving student attendance through family and community. Journal of Educational Research, 95, 308-318. doi:10.1080/00220670209596604

Evans, M. E., Armstrong, M. I., Kuppinger, A. D., Huz, S., \& McNulty, T. L. (1998). Preliminary outcomes of an experimental study comparing treatment foster care and family-centered intensive case management. In M. H. Epstein, K. Kutash, \& A. Duchnowski (Eds.), Outcomes for children and youth with emotional and behavioral disorders and their families: Programs and evaluation best practices. (pp. 543-580). Austin, TX: PRO-ED, Inc.

Federation for Community Schools. (2017). Strategies for braiding funds under the "Every Student Succeeds Act" to support community school development. Chicago, IL: Children's Home \& Aid. Retrieved on August 28, 2018, from http://www.ilcommunityschools.org/images /files/ESSA\%20support\%20for\%20community\%20schools\%2009-17.pdf

General Child \& Family Services Authority. (2014). Annual Report 2013-2014. Winnipeg, MB: Author. Retrieved from https://generalauthority.ca/files/Annual\%20Reports /General_CFS_Authority_2013-2014_Annual_General_Report.pdf

Government of New Brunswick. (2012). School/community partnerships and sponsorships. Retrieved September 5, 2018, from https://www2.gnb.ca/content/dam/gnb/Departments/ed/pdf/K12 /policies-politiques/e/315A.pdf

Government of Ontario. (2011). Open minds, healthy minds: Ontario's comprehensive mental health and addictions strategy (Provincial catalog no. 016277). Toronto, ON: Author. Retrieved from http://www.health.gov.on.ca/en/common/ministry/publications/reports /mental_health2011/mentalhealth_rep2011.pdf 
Government of Quebec. (2012). The community learning centre: A framework for action for Anglophone schools, centres and communities. Quebec City, QC: Author.

Harbin, G., McWilliam, R. A., \& Gallagher, J. J. (2000). Services for young children with disabilities and their families. In J. P. Shonkoff \& S. J. Meisels (Eds.), Handbook of early childhood intervention (2nd ed.; pp. 387-415). New York, NY: Cambridge University Press.

Heers, M., Van Klaveren, C., Groot, W., \& Maassen van den Brink, H. (2016). Community schools. Review of Educational Research, 86(4), 1016-1051.

Henig, J., Riehl, C. J., Houston, D. M., Rebell, M. A., \& Wolff, J. R. (2016). Collective impact and the new generation of cross-sector collaborations for education: A nationwide scan. New York, NY: Columbia University, Teachers College. Retrieved from www.tc.columbia.edu /education-policy-and-social-analysis/department-news/cross-sector-collaboration/

Hyde, K. L., Burchard, J. D., \& Woodworth, K. (1996). Wrapping services in an urban setting. Journal of Child \& Family Studies, 5(1), 67-82.

Jacobson, R., \& Blank, M. J. (2011). Expanding the learning day: An essential component of the community schools strategy. New Directions for Youth Development, 131, 55-67. doi:10.1002/yd.408

Kirby, M. J. L., \& Keon, W. J. (2006). Out of the shadows at last: Transforming mental health, mental illness and addiction services in Canada. Ottawa, ON: Standing Senate Committee on Social Affairs, Science and Technology.

Manitoba Health. (2011). Rising to the challenge: A strategic plan for the mental health and wellbeing of Manitobans. Winnipeg, MB: Government of Manitoba. Retrieved from https://www.gov.mb.ca/health/mh/docs/challenge.pdf

Manitoba Education. (2011). Grade 12 current topics in First Nations, Métis and Inuit studies: A foundation for implementation. Winnipeg, MB: Government of Manitoba. Retrieved from https://www.edu.gov.mb.ca/k12/abedu/foundation_gr12/full_doc.pdf

Manitoba Education and Training. (2018). Special needs funding criteria level 2 and 3. Winnipeg, MB: Government of Manitoba. Retrieved from https://www.edu.gov.mb.ca/k12/specedu /funding/level2-3.htm

McIntosh, K., Moniz, C., Craft, C. B., Golby, R., \& Steinwand-Deschambeault, T. (2014). Implementing school-wide positive behavioural interventions and supports to better meet the needs of Indigenous students. Canadian Journal of School Psychology, 29(3), 236-257.

Mears, S. L., Yaffe, J., \& Harris, N. J. (2009). Evaluation of wraparound services for severely emotionally disturbed youths. Research on Social Work Practice, 19(6), 678-685.

Mental Health Commission of Canada. (2012). Changing directions, changing lives: The mental health strategy for Canada. Calgary, AB: Author. Retrieved from https://www.mentalhealthcommission.ca/sites/default/files/MHStrategy_Strategy_ENG.pdf

Mental Health Commission of Canada. (2013). Making the case for investing in mental health in Canada. Calgary, AB: Author. Retrieved from https://www.mentalhealthcommission.ca /sites/default/files/2016-06/Investing_in_Mental_Health_FINAL_Version_ENG.pdf

Merriam, S. 1998. Qualitative research and case study applications in education. San Francisco, CA: Jossey-Bass.

Miles, P., Brown, N., \& the National Wraparound Initiative Implementation Work Group. (2008). The wraparound implementation guide: A handbook for administrators and managers. Online publication. Portland, OR: National Wraparound Initiative. Retrieved from https://nwi.pdx.edu/pdf/ImplementationGuide-Complete.pdf 
Moll, L., Amanti, C., Neff, D., \& González, N. (2005). Funds of knowledge for teaching: Using a qualitative approach to connect homes and classrooms. In N. González, L. Moll, \& C. Amanti (Eds.), Funds of knowledge: Theorizing practices in households, communities, and classrooms (pp. 71-87). Mahwah, NJ: Lawrence Erlbaum.

Myaard, M. J., Crawford, C., Jackson, M., \& Alessi, G. (2000). Applying behavior analysis within the wraparound process: A multiple baseline study. Journal of Emotional \& Behavioral Disorders, 8, 216-229.

National Research Council and Institute of Medicine. (2009). Preventing mental, emotional, and behavioral disorders among young people: Progress and possibilities. Washington, DC: The National Academies Press. doi:10.17226/12480

National Wraparound Initiative. (n.d.). Mission of the National Wraparound Initiative [Webpage]. Portland, OR: Author. Retrieved August 28, 2018, from https://nwi.pdx.edu/mission-of-the-nwi/

Nova Scotia Department of Education. (2015). Education and early childhood development [Webpage]. Halifax, NS: Government of Nova Scotia. Retrieved on August 31, 2018 from https://schoolsplus.ednet.ns.ca/

Olibris, B., Mulvale, G., Carusone, S., Lin, E., Domonchuk-Whalen, M., \& Whittaker, K. (2017). Spotlight on Caroline Families First wraparound program: Lessons for advancing collaborative family-centred care for complex child and youth mental health. Canadian Journal of Community Mental Health, 36(2), 191-204.

Osher, T. W., \& Penn, M. (2010). How family partners contribute to the phases and activities of the wraparound process. In E. J. Bruns \& J. S. Walker (Eds.), Resource guide to wraparound. Online publication. Portland, OR: National Wraparound Initiative. Retrieved from https://nwi.pdx.edu/NWI-book/Chapters/Osher-4b.2-(fam-partner-phases-activities).pdf

Pagkos, B. M. (2011). The effect of wraparound practice ideology and care coordinator practices on client outcomes (Doctoral dissertation). University of Buffalo, Buffalo, NY. Retrieved from ProQuest Information \& Learning.

Painter, K., Allen, J. S., \& Perry, B. (2011). Families' experiences in wraparound: A qualitative study conceived and conducted by families through a professional-family collaboration. Journal of Emotional and Behavioral Disorders, 19(3), 156-168. doi:10.1177/1063426610364842

Prince Edward Island Department of Workforce and Advanced Learning. (2016). Prince Edward Island association of community schools [Webpage]. Retrieved October 10, 2018 from https://www.princeedwardisland.ca/en/information/workforce-and-advanced-learning/princeedward-island-association-community-schools

Pullmann, M. D., Kerbs, J., Koroloff , N., Veach-White, E., Gaylor, R., \& Sieler, D. (2006). Juvenile offenders with mental health needs: Reducing recidivism using wraparound. Crime and Delinquency, 52, 375-397.

Raffo, C., \& Dyson, A. (2007). Full service extended schools and educational inequality in urban contexts: New opportunities for progress? Journal of Education Policy, 22, 263-282. doi:10.1080/02680930701269160

Schachter, H., Girardi, A., Ly, M., Lacroix, D., Lumb, A., van Berkom, J., \& Gill, R. (2008). Effects of school-based interventions on mental health stigmatization: A systematic review. Child and Adolescent Psychiatry and Mental Health, 2(18), 1-14.

Schurer Coldiron, J., Bruns, E., \& Quick, J. (2017). A comprehensive review of wraparound care coordination research, 1986-2014. Journal of Child and Family Studies, 26(5), 1245-1265.

Scott, T. M., McIntyre, J., Liaupsin, C., Nelson, C. M., Conroy, M., \& Payne, L. D. (2005). An examination of the relation between functional behavior assessment and selected intervention strategies with school-based teams. Journal of Positive Behavior Interventions, 7(4), 205-215. 
Scott, T. W., \& Eber, L. (2003). Functional assessment and wraparound as systemic school processes: Primary, secondary, and tertiary systems examples. Journal of Positive Interventions, 5, 131-143.

Simons, D., Pires, S. A., Hendricks, T., Lipper, J. (2014). Intensive care coordination using highquality wraparound for children with serious behavioral health needs: State and community profiles. Hamilton, NJ: Center for Health Care Strategies, Inc. Retrieved from https://www.chcs.org/resource/intensive-care-coordination-using-high-quality-wraparoundchildren-serious-behavioral-health-needs-state-community-profiles/

Skrtic, T. M. (1995). Disability and democracy: Reconstructing (special) education for postmodernity. New York, NY: Teachers College Press.

Smith-Moncrieffe, D. (2014). Youth Gang Prevention Fund projects: What did we learn about what works in preventing gang involvement? Ottawa, ON: National Crime Prevention Centre, Public Safety Canada.

Thompson, D. R., Iachan, R., Overpeck, M., Ross, J. G., \& Gross, L. A. (2006). School connectedness in the health behavior in school-aged children study: The role of student, school, and school neighborhood characteristics. Journal of School Health, 76, 379-386. doi:10.1111/j.17461561.2006.00129.x

Toronto District School Board. (2015). Priority schools initiative [Webpage]. Retrieved on August 31, 2018, from http://www.tdsb.on.ca/community/communityuseofschools /priorityschoolsinitiative.aspx

Tymchak, M., \& the Saskatchewan Instructional Development and Research Unit. (2001). School Plus: A vision for children and youth: Toward a new school, community, and human service partnership in Saskatchewan. Regina, SK: Task Force on the Role of the School. Retrieved on August 31, 2018, from https://edadm821.files.wordpress.com/2013/01/schoolplus-finalreport.pdf

VanDenBerg, J., \& Grealish, E. M. (1998). The wraparound process: Training manual. Pittsburgh, PA: The Community Partnerships Group.

VanDenBerg, J., \& Rast, J. (2003). Wraparound coaching and supervision toolkit. Englewood, CO: Vroon VanDenBerg.

Waddell, C., McEwan, K., Shepherd, C., Offord, D. R, \& Hua, J. M. (2005). A public health strategy to improve the mental health of Canadian children. Canadian Journal of Psychiatry, 50(4), 226-233.

Waddell, C., Shepherd, C. A., Schwartz, C., \& Barican, J. (2014). Child and youth mental disorders: Prevalence and evidence-based interventions. Vancouver, BC: Children's Health Policy Centre, Simon Frazer University.

Walker, J. S. (2008). Supporting wraparound implementation: Overview. In E. J. Bruns \& J. S. Walker (Eds.), Resource guide to wraparound. Online publication. Portland, OR: National Wraparound Initiative. Retrieved from https://nwi.pdx.edu/NWI-book/Chapters/Walker-5a.1(support-wrap-implement).pdf

Walker, J. S., Bruns, E. J., \& Penn, M. (2008). Individualized services in systems of care: The wraparound process. In B. Stroul \& G. Blau (Eds.), The system of care handbook: Transforming mental health services for children, youth, and families. Baltimore, MD: Brookes.

Walker, J. S., Koroloff, N., \& Schutte, K. (2003). Implementing high-quality collaborative individualized service/support planning: Necessary conditions. Portland, OR: Research and Training Center on Family Support and Children's Mental Health

Walker, J. S., \& Sanders, B. (2011). The Community Supports for Wraparound Inventory: An assessment of the implementation context for wraparound. Journal of Child and Family Studies, 20(6), 747-757. doi:10.1007/s10826-010-9432-1 
Wallace, L., Debicki, A., Vander Vennen, M., \& de Visch Eybergen, E. (2012). Canadian wraparound: A case study of a volunteer-driven, community-based approach for families, children, and youth with complex needs in Hamilton, Ontario. Relational, Child and Youth Care Practice, 27(4), 53-66.

Whitley, J. (2014). Supporting educational success for Aboriginal students: Identifying key influences. McGill Journal of Education, 49(1), 155-181. doi:10.7202/1025776ar

Whitley, J., \& Gooderham, S. (2016). Exploring mental health literacy among pre-service teachers. Exceptionality Education International, 26, 62-92. Retrieved from https://ir.lib.uwo.ca/eei /vol26/iss $2 / 5$

Yukon Health and Social Services. (2012). Whole child program, Whitehorse [Webpage]. Retrieved on August 31, 2018 from provincial Pathways to Wellness website, http://www.yukonwellness.ca/stories_whole.php\#.VYDEpWrwupo

World Health Organization. (2013). Comprehensive mental health action plan. Geneva, Switzerland: Author. Retrieved from http://apps.who.int/iris/bitstream/10665/89966/1/9789241506021 _eng.pdf?ua $=1 p$

Zigler, E. F., Finn-Stevenson, M., \& Stern, B. (1997). Supporting children and families in the schools: The school of the 21st century. American Journal of Orthopsychiatry, 67(3), 396-406.

\section{Authors' Note}

Correspondence concerning this article should be addressed to Dr. Nadine Bartlett, Faculty of Education, University of Manitoba, R3T 2N2, Canada. Email: nadine.bartlett@umanitoba.ca 